\title{
Masters and Commanders
}

\author{
Considering the Concept of the Edited Text
}

\author{
Josephine Koster
}

\begin{abstract}
This essay considers the problematic nature of textual editing in the age of digitized and digital editions. Scholars consistently seek to identify "best" editions and to establish the identities of scribes like Adam Pynkhurst beyond a reasonable doubt, but experience shows how difficult such identifications can be, even when undertaken by qualified scholars with full access to the texts in question. Given the instability of technologies, the need for sustainability in digital platforms, and the difficulties in producing "final" print editions of medieval texts that exist in multiple witnesses, the essay argues that editorial closure may be an impossible goal.
\end{abstract}

'When I use a word,' Humpty Dumpty said, in rather a scornful tone, 'it means just what I choose it to mean - neither more nor less.'

'The question is,' said Alice, 'whether you can make words mean so many different things.'

'The question is,' said Humpty Dumpty, 'which is to be master - that's all.'

Through the Looking Glass, ch. 6

$\mathrm{T}_{\mathrm{H}}$

HE FIRST SCHOLARLY PROJECT I EVER UNDERTOOK WAS TO EDIT A previously-unpublished Middle English poem that is uniquely preserved in the flyleaves of a Wycliffite New Testament at the University of Pennsylvania, now listed as MS Codex 201 (PENN AT HAND), which became not only the subject of my master's thesis but my first publication. I spent a great deal of my graduate education immersed in photocopies of Piers Plowman manuscripts on the sidelines of the Athlone Piers Plowman editions, and was taught my editorial practices and theory by George Kane. And off and on for the last two decades I have been trying to untangle the editorial situation and contexts of medieval texts associated with fifteenth-century female authors, while at the same time I have been working with hypertext 
and multimedia authorship and their related issues. Textual editing, a practice which has been called into question by the literary theorists of the last three decades, has been at the center of my professional career as a medievalist. So when I ask about the standard or best edition of such-and-such text, I do so not only as scholar and teacher, but as creator and editor as well. It is indeed a an uncomfortable place to stand. Thorlac Turville-Petre ruefully quipped, "The definitive critical edition is only definitive until the next one comes along" (Turville-Petre 2013, 55) - that is, if there can be a definitive critical edition of any medieval text in the first place.

In summer 2014, a conversation took place on one of the leading medieval list-servs that illustrates some of the challenges and perplexities involved in editing medieval texts in the 21st century. Late at night on a holiday weekend, a young scholar working on his first book had a question about which editions of certain major European texts he should cite as evidence. Like a good 21st century scholar, he turned to the internet and crowdsourced his inquiry. His training was in British languages, he wrote, and he was seeking advice on standard editions of texts outside his area of expertise. Before dawn, a retired and respected professor had answered the questions about several French texts, but his comments on another text set off a cybernetic storm. He recommended a particular 1960's translation of a particular Continental work, though he admitted he hadn't written on that author in a while. He gave no reason for preferring it; and his recommendation did not go unchallenged. Why not?

The next two days were dominated by long and erudite, anecdote-filled posts about scholarly editions. The young scholar was advised by one respondent to consult, but not cite, a 1970's translation because of presumed inaccuracies and consider using an underappreciated 1980's translation by another scholar instead. Another professor quickly rebutted this preference, telling the young scholar that most modern English editions are based, more or less closely, on a particular early modern edition; this scholar recommended a more recent prose translation instead, because its lines were laid out as if they were the verse form of the original (even though the translation was not in verse). A wizened veteran teacher told the young scholar that editions didn't matter, because all current editions are based on a text that wasn't accurate and that really, no one knows what the "best" text of that work is for scholarly purposes. By the end of the 26-message exchange, the battered young scholar who started the thread was even more perplexed. He lamented that his graduate training had not prepared him to identify "best editions" of some of the most important works in the field, but he had a bright idea: Perhaps people on the list 
could crowdsource an online list of authoritative texts that scholars like him could consult. He concluded that he'd be willing to start the creation of such a list, but not until after he submitted his tenure packet, because he didn't think that the tenure and promotion committees at his institution would support his interest in textual editing.

A plaintive wish for authoritative answers and commentary in a postmodern (and post-tenure) age - I think we can all sympathize with this young scholar's plight. Just tell us who's right, who's in charge, what it all means, and then we can go on with our work. As Humpty Dumpty pointed out, the question is who has the mastery - and in a case as complex as this one, clearly no one can give a final answer. Nor, upon examination, is the young scholar's list of crowd-sourced authorities an answer to the problem, since it would presumably be based upon individual preferences and experiences, not a list of consistent and accepted criteria.

Most of my own work has been with texts in British languages and Latin, but my language skills are sufficient to hack out a literal, word-byword prose translation of most European medieval works if I have to, so long as there's a dictionary to hand. But I'm fully aware that in so doing, I am giving weight to Robert Frost's dictum that what gets lost in translation is the poetry - the music behind the words. On the other hand, poetic quality is not always enough to sell me on a translation; I'm part of the group that finds Seamus Heaney's Beowulf to be excellent modern poetry, but more Celtic than Anglo-Saxon in effect. In the end, I am no different than those pundits giving our young scholar advice on a weekend night. Turville-Petre's wry observation might well be altered to read "The definitive critical edition is only definitive until the one I like better comes along".

The young scholar, though, points us away from print editions to another conundrum in editorial practice - the internet. Remember how it was going to save us from all these contested editorial decisions? Online editions with their multi-modal potential, Stephen Reimer argued, would allow us to take in all the metatextual and paratextual information we would get if we read a text in the actual medieval manuscript:

The modern printed edition focuses exclusively on the words; all nonlinguistic elements, here specifically the decoration and illustration, have been erased in the process. The printed edition reduces this complex 'multimedia' work to mere alphabetic characters. A kind of translation has taken place, and the edited text is not the same as the manuscript text, even if the words are the same.... we as editors have been guilty of 
logocentrism in several senses, not least a tendency to isolate the textual and extract it from the stream of the reading experience, fetishizing the word while dismissing the pictures, the music, and the other elements which may have been part of the original whole composition. (REIMER 2004, 168)

The Internet was going to save us from ourselves and our bowdlerized print editions. Too bad that it has so far shown itself inconsistently capable of doing so.

Bella Millet, in a recent and lovely essay entitled "Whatever happened to electronic editing?" sums up the theoretical reasons why print editions of vernacular literary texts are always doomed to inadequacy. The techniques of editing developed by philologists from the early nineteenth century onwards, she argues, were inappropriate for many medieval vernacular works, since their textual tradition was fluid and non-hierarchical, and the Bedierist 'best text' edition is too isolated from the broader textural tradition of a work; and even separate editions of multiple manuscripts of a work, or parallel-text editions, are limited by the format of the print codex. (Millet 2013, 39-46 passim). I try to imagine, for instance, what a parallel-text edition of The Prik of Conscience would look like; it's a nightmare, and makes James H. Morey's comment in the introduction to the TEAMS edition fully understandable: "Given the number of extant manuscripts of the Prik of Conscience an editorial reconstruction would be most unwieldy. A single-text edition, such as this one, honors the work of the medieval poet and scribe who is not only a compiler but also a reader of his manuscript sources" (MOREy 2012). But the early excitement about online editions has diminished greatly in the last decade and a half. The Canterbury Tales project hasn't published a new text since 2006 because of rights issues; the online Variorum Chaucer never got off the ground. The Piers Plowman Project puts out interesting CDs, but has generated very small sales. Many of the earliest digital texts are now unreadable, their programming not having been updated for more modern operating systems. Turville-Petre points out that the process of creating the kinds of searchable electronic editions that are desired is one fraught with difficulties and contradiction. In a discussion of how electronic editors decide what and how to tag elements in a text, involving a series of editorial judgments and priorities that rivals those of Kane and Donaldson's deep editing, Turville-Petre writes:

It is necessary to record everything on the leaf, not just the text: the layout, paraphs, colours, punctuation (or is it just a blot?), changes of hand, 
corrections, marginal annotations, and damage. All these features have to be tagged so that they can be displayed and searched. The opportunities for error is multiplied, and everything has to be proofread again and again until it is right; otherwise it is worthless. $(2013,66)$

The status of critical editing, Jerome McGann noted just a few years ago, is ". . . stranded in a kind of half-world between print and digital technologies" with no clear road to the future (2011). Common words one now hears in discussion of online editions and archives are "sustainability" and "economics", as the cost of producing and maintaining such resources is seen as a growing impediment in the academic and publishing communities. Our young scholar's request for an editorial wiki, one that would continuously identify, update, and presumably hyperlink to online "best" texts of critical editions, is probably doomed to failure from the start. Once again, we confront the question of the authority of textual editions - can there only be a single best edition of a work? Can there be best editions for specialists, for non-specialists, for teachers of future specialists, and for teachers of students who may never read these texts again? Is the market for such ranges of texts sustainable? Is the academic reward for preparing such texts commensurate with the energy, time, and resources needed to make so many different alternatives available? This may indeed be the greatest challenge facing editors of medieval texts in the 21st century: justifying the ways of copytext to people who think they can Google an acceptable substitute for anything.

Maybe these would not be such important issues if more scholars of medieval literature had access to primary manuscripts, the paleographical training to assess them, and the historical, linguistic, cultural, literary, and other kinds of expertise it takes to recognize the potential problems in texts and the ways in which they could be read. This knowledge is comprehensive, as Tim William Machan points out: "to produce a properly historical document, one must attempt to recover what lies behind the individual manuscript; it is not enough to reproduce what one medieval reader read, because that reader inevitably supplemented his or her copy with a variety of literary and cultural contexts" $(1994,184)$. But not all of us have that access or that expertise, and so we remain dependent on the voices of the "experts" who opine on our texts. A good case in point is the current infatuation with Adam Pynkhurst, the English scribe who may have copied some of Chaucer's manuscripts in the decade following the poet's death and whom some scholars would like to identify with Parkes and Doyle's Hand B in the Hengwrt and Ellesmere manuscripts of the Canterbury 
Tales. Only a dozen years have passed since Linne Mooney announced at the 2004 New Chaucer Society meeting that she had identified the hand of Chaucer's "Adam Scriveyn" and yet it is becoming more and more common to see scholars talking about Adam Pynkhurst's role as Chaucer's copyist, possible editor, and even literary executor. Like our young scholar who wanted a concrete identification of the "right" editions of medieval texts, it seems that Chaucer scholars - many of whom have enough editorial and paleographical training to know better-have accepted, almost uncritically, Mooney's thesis that Pynkhurst is Scribe B. Since the identification rests on knowing the minutiae of scribal practices and orthographic styles used in London in the late fourteenth and early fifteenth centuries, and access to a number of manuscripts that aren't available digitally, it's hard for outsiders - even experts in medieval literature - to challenge Mooney's identification. Yet the grounds for such challenge are plentiful. In a 2011 article in Medium Aevum Jane Roberts showed how, in a period of only five years, the number of manuscripts attributed to Pynkhurst mushroomed, even as she clearly presents the paleographic evidence why we should not rush to accept Mooney's thesis. A. S. G. Edwards has recently reinforced Roberts' doubts in his review of Mooney and Stubb's book in The Library, and Lawrence Warner has raised further challenges to the identification of Pynkhurst in a recent article in Studies in the Age of Chaucer.

For all our postmodern strictures about ambiguity, it seems that medievalists really seek editorial closure, even when the evidence is shaky at best. Not every scholar has access to the Guildhall letterbooks, the petitions of the Mercer's company, or the register of the guild of Stationers to do the detective work themselves. I suspect that the identification of Adam Pinkhurst is going to become the 21st century equivalent of the Chaucer Society's reworking of the last lines of the Parson's Prologue to fit Victorian notions of correct narrative flow, in total defiance of all the manuscripts; even the Riverside Chaucer perpetuates this editorial arrogance, with the information about it buried in two remote footnotes in two widely-separated sets of appendices. In modern times, it wasn't until the appearance of the Norton Critical Edition of nine of the Canterbury Tales that the lines were silently returned to their manuscript order, in which the last word of poetry in the entire work is "grace". Certainly there have been scholars who have known about this problem over the years, and complained about it and pointed it out, but the "standard scholarly edition" of Chaucer still preserves this Victorian reworking. Likewise, I'm sure that many of us will be telling our students for years to come that Adam Pynkhurst may have copied literary manuscripts, though we're not sure he's Chaucer's "own 
scribe Adam" as Shirley called him — but that scholarly works will go on naming him as Hand B for years to come.

So Humpty Dumpty's question that I cited at the beginning of this essay goes straight to the heart of the nature of editorial and critical practices - when we create editions, when we dub them "standard" or "best" or "recommended", we are empowering those editions, and authorizing users to replicate our beliefs without critically examining the assumptions on which they are based. Is it even possible in these days of critical and textual doubt to have a "standard edition" of a text that has multiple witnesses, like The Divine Comedy or The Prik of Conscience or Piers Plowman? Is it possible to accept an edition that decontextualizes the text - such as Klaeber's Beowulf — as being the recommended scholarly version of the poem? If a scholar sends a journal a Chaucer article that uses the Norton Critical edition of the Parson's Prologue instead of the Riverside edition, should the editor insist on changes? If a scholarly edition on CD can no longer be read by our Mac Books and tablets, is it still a scholarly edition? These are among the questions that face us as we deal with editorial practices in medieval studies today. There are no simple answers, only differing perspectives.

\section{Works Cited}

Edwards, A.S.G. 2014. Review of Scribes and the City. The Library 15.1: 79-81.

Machan, Tim Williiam. 1994. Textual Criticism and Middle English Texts. Charlottesville: University of Virginia Press, 1994.

McGann, Jerome. 2011. Online Humanities Scholarship: The Shape of Things to Come. Connexions. http://cnx.org/contents/PVdH0-1D@1.3:kfHOufNB@2/Introduction.

Millet, Bella. 2013. "Whatever Happened to Electronic Editing?" In Probable Truth: Editing Medieval Texts from Britain in the Twenty-First Century. Edited by Vincent Gillespie and Anne Hudson, 39-54. Turnhout: Brepols.

Morey, James H. 2012. "Introduction". The Prik of Conscience. TEAMS Edition. Rochester: TEAMS Middle English Text Series. http://d.lib.rochester.edu/teams/ text/morey-prik-of-conscience-introduction.

Penn In Hand. Ms. Codex 201 (New Testament in the Translation of John Wycliffe). http://dla.library.upenn.edu/dla/medren/pageturn.html?id=MEDREN_1551783.

Reimer, Stephen. 2004. "Unbinding Lydgate's Lives of Saints Edmund and Fremund". In The Book Unbound: Editing and Reading Medieval Manuscripts and Texts, 16789. Edited by Siân Echard and Stephen Partridge. Toronto: University of Toronto Press, 2004.

Roberts, Jane. 2011. "On Giving Scribe B a Name and a Clutch of London Manuscripts from c. 1400". Medium Aevum 80: 247-70. 
Turville-Petre, Thorlac. 2013. "Editing Electronic Texts". In Probable Truth: Editing Medieval Texts from Britain in the Twenty-First Century, 55-70. Edited by Vincent Gillespie and Anne Hudson. Turnhout: Brepols.

Warner, Lawrence. 2015. "Scribes, Misattributed: Hoccleve and Pinkhurst". Studies in the Age of Chaucer 37: 55-100. 